\title{
On the Mechanism of the Hydroxylation of the Thianthrene Cation Radical in Acetonitrile and Dichloromethane
}

\author{
OLE HAMMERICH ${ }^{\mathrm{a}}$ and VERNON D. PARKER ${ }^{\mathrm{b}}$
}

a Department of General and Organic Chemistry, The H. C. Ørsted Institute, University of Copenhagen, Universitetsparken 5, DK-2100 Copenhagen, Denmark and ${ }^{\mathrm{b}}$ Organic Chemistry Laboratories, Norwegian Institute of Technology, University of Trondheim, N-7034 Trondheim-NTH, Norway

The rate law for the reaction between thianthrene cation radical $\left(\mathrm{Th}^{+}\right)$and water in dichloromethane containing trifluoroacetic acid (TFA) resembles that established earlier for the reactions of $\mathrm{Th}^{+}$ with anisole or phenol (i) and suggests the complex reaction schemes (ii)-(iv). The inhibition of the

Rate $=k_{\text {app }}\left[\mathrm{Th}^{+}\right]^{2}\left[\mathrm{H}_{2} \mathrm{O}\right] /$ (constant + [Th])[TFA $]^{2}$

$\mathrm{Th}^{++}+\mathrm{H}_{2} \mathrm{O} \rightleftarrows \mathrm{Th}^{+} / \mathrm{H}_{2} \mathrm{O}$

$\mathrm{Th}^{++} / \mathrm{H}_{2} \mathrm{O}+\mathrm{Th}^{++} \rightleftarrows \mathrm{Th}^{2+} / \mathrm{H}_{2} \mathrm{O}+\mathrm{Th}$

$\mathrm{Th}^{2+} / \mathrm{H}_{2} \mathrm{O} \rightarrow$ products

reaction by TFA is attributed to the deactivation of water. Earlier kinetic data reported for the reaction in acetonitrile are re-examined and found to be consistent with a similar mechanism.

In previous publications ${ }^{1,2}$ it has been shown that the reactions of the thianthrene cation radical $\left(\mathrm{Th}^{+}\right)$with nucleophiles can be described by the general reaction scheme (1)-(3). The features of

$\mathrm{Th}^{++}+\mathrm{Nu} \underset{k_{-1}}{\stackrel{k_{1}}{\rightleftarrows}} \mathrm{Th}^{++} / \mathrm{Nu}$

$\mathrm{Th}^{++} / \mathrm{Nu}+\mathrm{Th}^{+} \underset{k_{-2}}{\stackrel{k_{2}}{\rightleftarrows}} \mathrm{Th}^{2+} / \mathrm{Nu}+\mathrm{Th}$

$\mathrm{Th}^{2+} / \mathrm{Nu} \stackrel{k_{3}}{\longrightarrow}$ products

the kinetic data which support this mechanism are the appearance of a constant and [Th] in the denominator of the rate law. Mechanism (1) to (3) can then be described by rate law (4) which is consistent with the observed kinetics.

Rate $=2 k_{3} K_{1} K_{2}\left[\mathrm{Th}^{+}\right]^{2}[\mathrm{Nu}] /\left(k_{3} / k_{-2}+[\mathrm{Th}]\right)$

A more recent kinetic study on the mechanism of the reaction of $\mathrm{Th}^{+}$with water in acetonitrile led to the formulation of rate law (5) and mechanism $(6)-(9){ }^{3}$ This mechanism has been considered

$$
\begin{aligned}
& \text { Rate }=2 k_{8} K_{6}^{2} K_{7}\left[\mathrm{Th}^{++}\right]^{2}\left[\mathrm{H}_{2} \mathrm{O}^{3} /\left[\mathrm{H}_{2} \mathrm{O}^{+}\right]\right. \\
& \mathrm{Th}^{++}+\mathrm{H}_{2} \mathrm{O} \underset{k_{-6}}{\stackrel{k_{6}}{\rightleftarrows}} \mathrm{Th}\left(\mathrm{OH}_{2}\right)^{+} \\
& \mathrm{Th}\left(\mathrm{OH}_{2}\right)^{+}+\mathrm{H}_{2} \mathrm{O} \underset{k_{-7}}{\stackrel{k_{7}}{\rightleftarrows}} \mathrm{Th}(\mathrm{OH})^{-}+\mathrm{H}_{3} \mathrm{O}^{+} \\
& \mathrm{Th}(\mathrm{OH})^{-}+\mathrm{Th}\left(\mathrm{OH}_{2}\right)^{++} \stackrel{k_{8}}{\longrightarrow} \mathrm{Th}+\mathrm{Th}(\mathrm{OH})^{+}+\mathrm{H}_{2} \mathrm{O}
\end{aligned}
$$

$\mathrm{Th}(\mathrm{OH})^{+}+\mathrm{H}_{2} \mathrm{O} \stackrel{\text { fast }}{\longrightarrow} \mathrm{ThO}+\mathrm{H}_{3} \mathrm{O}^{+}$

to be established in a recent review article. ${ }^{4}$ The essential difference between mechanism (6)-(9) and that observed in the presence of other nucleophiles, (1)-(3), is that the primary electrophilic reaction which involves bond formation between the thianthrene and nucleophile moieties involves the cation radical, eqn. (6), in the one case and the dication, eqn. (3) in the other. The third order dependence on $\left[\mathrm{H}_{2} \mathrm{O}\right]$ is the feature of the rate data for the reaction in acetonitrile that diverges most from all of the other kinetic data available for the reactions of $\mathrm{Th}^{+}$with nucleophiles. An unsavory 
feature of this mechanism is that in order for rate law (5) to hold, equilibrium (7) must be displaced strongly to the left, otherwise $\mathrm{H}_{3} \mathrm{O}^{+}$would not significantly alter the concentration of $\operatorname{Th}(\mathrm{OH})$. Furthermore, in order that $\left[\mathrm{H}_{2} \mathrm{O}\right]$ influence the effective concentration of $\mathrm{Th}\left(\mathrm{OH}_{2}\right)^{++}$, equilibrium (6) must be displaced strongly to the left as well. However, the mechanism requires that $\mathrm{Th}\left(\mathrm{OH}_{2}\right)^{-+}$ be the oxidant even though $\mathrm{Th}^{+}$will be present in much higher concentration. The uncomplexed cation radical would be expected to be a better oxidant than $\mathrm{Th}\left(\mathrm{OH}_{2}\right)^{+}$which suggests that eqn. (8) in the mechanism will be insignificant in comparison to reaction (10). When this is taken into

$\mathrm{Th}(\mathrm{OH})^{+}+\mathrm{Th}^{+} \stackrel{k_{10}}{\longrightarrow} \mathrm{Th}(\mathrm{OH})^{+}+\mathrm{Th}$

account the rate law becomes (11). It is therefore our opinion that the mechanism proposed by Evans

Rate $=2 k_{10} K_{6} K_{7}\left[\mathrm{Th}^{++}\right]^{2}\left[\mathrm{H}_{2} \mathrm{O}\right]^{2} /\left[\mathrm{H}_{3} \mathrm{O}^{+}\right]$

and Blount ${ }^{3}$ is inconsistent with the kinetic data presented and further work is required to establish the mechanism of the hydroxylation of thianthrene cation radical.

\section{RESULTS AND DISCUSSION}

Kinetics of complex ion radical reactions. For the general case of the reaction of an ion radical (A) with $B$, a species capable of complexing with $A$, the intermediate complex $\mathrm{A} / \mathrm{B}$ will generally not be distinguishable from $A$ by the kinetic measurement technique. The overall reaction, eqns. (12)-(13),

$\mathrm{A}+\mathrm{B} \stackrel{K_{12}}{\rightleftarrows} \mathrm{A} / \mathrm{B}$

$\mathrm{A} / \mathrm{B} \stackrel{k_{13}}{\longrightarrow}$ products

can give rise to either first order, mixed order, or second order kinetics depending upon the magnitude of $K_{12}$. The situation can be even more complicated if reaction (12) cannot be considered to be in equilibrium. If $K_{12}$ is large the rate law is (14)

Rate $=-\mathrm{d}[\mathrm{A} / \mathrm{B}] / \mathrm{d} t=k_{13}[\mathrm{~A} / \mathrm{B}]$

and providing that $B$ is in excess, as is usually the case, the rate is independent of the concentration of B. On the other hand, if $K_{12}$ is small, rate law (15) is valid. The intermediate case where $K_{12}$ is
Rate $=-\mathrm{d}[\mathrm{A}] / \mathrm{d} t=k_{13} K_{12}[\mathrm{~A}] /[\mathrm{B}]$

approximately unity is described by eqn. (16) which takes into account the monitoring of two different

Rate $=-\mathrm{d}[\mathrm{A}] / \mathrm{d} t-\mathrm{d}[\mathrm{A} / \mathrm{B}] / \mathrm{d} t$

species giving rise to non-integral reaction orders and is difficult to use in the evaluation of kinetic data. Thus, the two useful cases are those giving either first or second order kinetics.

The analysis of Evans and Blount which gave rise to rate law (5) involved the implicit assumption that $\mathrm{Th}^{+}$does not participate in reaction (8) which implies that the mechanism should be of the first general case where $K_{12}, K_{6}$ in the specific case, is large. However, they did not then use the proper rate expression which should have been $-\mathrm{d}\left[\mathrm{Th}\left(\mathrm{OH}_{2}\right]^{++} / \mathrm{d} t\right.$ instead of $-\mathrm{d}\left[\mathrm{Th}^{+}\right] / \mathrm{d} t$. The overall result then was to assign a reaction order of 3 instead of the correct value, either 2 when $K_{6}$ is small or 1 when $K_{6}$ is large, for water in mechanisms (6)-(9).

The kinetics of the reaction of thianthrene cation radical with water in dichloromethane-trifluoroacetic acid. In the presence of excess Th, water, and

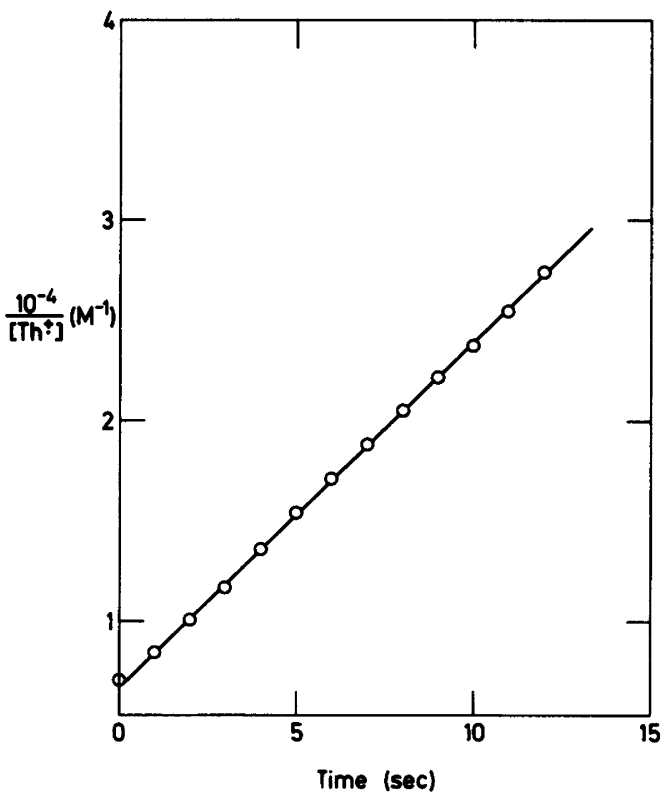

Fig. 1. Second order rate plot for the hydroxylation of thianthrene cation radical in dichloromethane containing thianthrene $(0.00548 \mathrm{M})$, TFA $(0.0275$ $\mathrm{M})$ and water $(0.0484 \mathrm{M})$. 
Table 1. The dependence of the apparent second order rate constant on the thianthrene concentration. ${ }^{a}$

\begin{tabular}{llll}
\hline Run & $\begin{array}{l}{[\mathrm{Th}]_{0} \times 10^{3}} \\
(\mathrm{M})\end{array}$ & $\begin{array}{l}k_{\text {obs }} \times 10^{-4} \\
\left(\mathrm{M}^{-1} \mathrm{~s}^{-1}\right)\end{array}$ & $\begin{array}{l}1 / k_{\text {obs }} \times 10^{4} \\
(\mathrm{M} \mathrm{s})\end{array}$ \\
\hline 1 & 1.01 & 1.38 & 0.72 \\
2 & 2.73 & 0.984 & 1.02 \\
3 & 4.99 & 0.523 & 1.91 \\
4 & 7.27 & 0.413 & 2.42 \\
5 & 9.92 & 0.282 & 3.55 \\
\hline
\end{tabular}

${ }^{a}$ Reactions carried out in dichloromethane containing $\mathrm{Bu}_{4} \mathrm{NBF}_{4}(0.1 \mathrm{M})$, TFA $(0.0144 \mathrm{M})$ and water $(0.0484 \mathrm{M})$.

trifluoroacetic acid (TFA), the decay in $\mathrm{Th}^{+}$ follows a second order rate law. This is demonstrated by the data summarized in Figure 1 which were measured over approximately two half-lives of $\mathrm{Th}^{+}$. The effect of the initial thianthrene concentration $[\mathrm{Th}]_{0}$ on the observed second order rate constants $\left(k_{\text {obs }}\right)$ is illustrated by the data in Table 1 . Correlation of $\left(k_{\mathrm{obs}}\right)^{-1}$ vs. [Th] $]_{0}$ resulted in eqn. (17) with a correlation coefficient of 0.993 which $\left(k_{\text {obs }}\right)^{-1}=3.18 \times 10^{-2}[\mathrm{Th}]_{0}+2.8 \times 10^{-5}$

results in eqn. (18) after inversion. The dependence

$$
k_{\text {obs }}=31.4 /\left([\mathrm{Th}]_{\mathrm{o}}+8.8 \times 10^{-4}\right)
$$

of $k_{\mathrm{obs}}$ on the water concentration is shown by the data summarized in Table 2 at two different [TFA]. At both acid concentrations the calculated apparent third order rate constants were independent of $\left[\mathrm{H}_{2} \mathrm{O}\right]$ indicating a reaction order of 1.0 in water. The effect on the apparent rate constant of [TFA] is shown by the data in Table 3. The calculated rate constants in the last column assume a reaction order of -2 in TFA. The observed value, 5.18 $( \pm 0.15) \times 10^{3} \mathrm{M} / \mathrm{s}$, indicates a good fit to this relationship.

The mechanism of the hydroxylation of thianthrene cation radical. A mechanism consistent with the kinetic data is given by eqns. (19) - (22) which result in rate law (23). Reaction (19) indicates that the

$$
x \mathrm{H}_{2} \mathrm{O}+y \mathrm{TFA} \stackrel{K_{19}}{\rightleftarrows} \text { complex }
$$

Table 2. The effect of the water concentration on the apparent second order rate constant. ${ }^{a}$

\begin{tabular}{llllll}
\hline Run & $\begin{array}{l}{[\mathrm{Th}]_{\mathrm{o}} \times 10^{3}} \\
(\mathrm{M})\end{array}$ & $\begin{array}{l}{[\mathrm{TFA}]_{\mathrm{o}} \times 10^{2}} \\
(\mathrm{M})\end{array}$ & $\begin{array}{l}{\left[\mathrm{H}_{2} \mathrm{O}\right]_{\mathrm{o}} \times 10^{2}} \\
(\mathrm{M})\end{array}$ & $\begin{array}{l}k_{\text {obs }} \times 10^{-3} \\
\left(\mathrm{M}^{-1} \mathrm{~s}^{-1}\right)\end{array}$ & $\begin{array}{l}k_{\text {calc }} \times 10^{-3 b} \\
\left(\mathbf{M}^{-1} \mathbf{s}^{-1}\right)\end{array}$ \\
\hline 13 & 0.98 & 2.75 & 2.06 & 1.79 & 3.94 \\
14 & 0.99 & 2.75 & 4.84 & 5.00 & 3.92 \\
11 & 5.31 & 7.99 & 4.84 & 0.191 & 0.137 \\
15 & 5.18 & 7.99 & 7.62 & 0.343 & 0.140 \\
16 & 4.98 & 7.99 & 10.40 & 0.493 & 0.145 \\
\hline
\end{tabular}

${ }^{a}$ In dichloromethane containing $\mathrm{Bu}_{4} \mathrm{NBF}_{4}(0.1 \mathrm{M}) .{ }^{b}$ Corrected for variations in the thianthrene concentration.

Table 3. The effect of trifluoroacetic acid concentration on the apparent second order rate constant. ${ }^{a}$

\begin{tabular}{lllll}
\hline Run & $\begin{array}{l}{[\mathrm{Th}]_{\mathrm{o}} \times 10^{3}} \\
(\mathrm{M})\end{array}$ & $\begin{array}{l}{[\mathrm{TFA}]_{\mathrm{o}} \times 10^{2}} \\
(\mathbf{M})\end{array}$ & $\begin{array}{l}k_{\text {obs }} \times 10^{-4} \\
\left(\mathbf{M}^{-1} \mathbf{s}^{-1}\right)\end{array}$ & $\begin{array}{l}k_{\text {calc }} \times 10^{-4 b} \\
\left(\mathbf{M}^{-1} \mathbf{s}^{-1}\right)\end{array}$ \\
\hline 3 & 4.99 & 1.44 & 0.523 & 0.532 \\
6 & 5.48 & 2.75 & 0.167 & 0.490 \\
7 & 5.21 & 2.75 & 0.108 & 0.512 \\
8 & 5.06 & 5.37 & 0.0597 & 0.526 \\
9 & 5.00 & 5.37 & 0.0277 & 0.531 \\
10 & 5.04 & 6.68 & 0.0236 & 0.527 \\
11 & 5.31 & 7.99 & 0.0191 & 0.504 \\
12 & 5.08 & 7.99 & 0.0105 & 0.524 \\
\hline
\end{tabular}

\footnotetext{
${ }^{a}$ In dichloromethane containing $\mathrm{Bu}_{4} \mathrm{NBF}_{4}(0.1 \mathrm{M})$ and water $(0.0484 \mathrm{M}) .{ }^{b}$ Corrected for variations in the thianthrene concentration.
} 
$\mathrm{Th}^{++}+\mathrm{H}_{2} \mathrm{O} \underset{k_{-20}}{\stackrel{k_{20}}{\rightleftarrows}} \mathrm{Th}^{++} / \mathrm{H}_{2} \mathrm{O}$

$\mathrm{Th}^{+} / \mathrm{H}_{2} \mathrm{O}+\mathrm{Th}^{+} \underset{k_{-21}}{\stackrel{k_{21}}{\leftrightarrows}} \mathrm{Th}^{2+} / \mathrm{H}_{2} \mathrm{O}+\mathrm{Th}$

$\mathrm{Th}^{2+} / \mathrm{H}_{2} \mathrm{O} \stackrel{k_{22}}{\longrightarrow} \mathrm{ThO}+2 \mathrm{H}^{+}$

$-\mathrm{d}\left[\mathrm{Th}^{+}\right] / \mathrm{d} t=2 k_{22} K_{21} K_{20}\left[\mathrm{Th}^{+{ }^{+}}\right]^{2}\left[\mathrm{H}_{2} \mathrm{O}\right] /$

$\left(k_{22} / k_{-21}+[\mathrm{Th}]\right)$

function of TFA is to deactivate the water. Since protic equilibria can be complicated with a number of species involved, we do not wish to speculate on the detailed nature of the deactivation and (19) is only meant to signify a deactivation giving the required order in TFA. Mechanisms (20) to (22) and rate law (23) are identical to those found for reactions of both anisole ${ }^{1}$ and phenol ${ }^{2}$ with $\mathrm{Th}^{+}$ which were established some years ago. A noteworthy point is the implication of a reaction order of 1 for water in this reaction. Water is surely the strongest base in the system. If proton transfer occurred before the rate determining step, a reaction order of 2 is expected for water. This implies that reaction (22) involves the formation of the $\mathrm{S}-\mathrm{O}$ bond followed by rapid proton transfer.

The mechanism of the reactions of cation radicals with nucleophiles is frequently referred to as the half-regeneration mechanism. ${ }^{3,4,7}$ The half-regeneration term arises from the fact that the ion radical is an odd electron species and after reaction, regardless of the mechanism, with a nucleophile a second equivalent of the cation radical is necessary to achieve a stable oxidation state. What our kinetic studies have established ${ }^{1,2,5,6}$ is that the cation radicals are the reactive species and that they initially form a complex with the nucleophiles in which formal bonding has not taken place. The second order in cation radical then arises because electron transfer to give the dication is necessary before irreversible bond formation occurs. For want of a better term, we have called this the "complexation mechanism".

\section{EXPERIMENTAL}

Dichloromethane was reagent grade and passed through a column of neutral alumina (Woelm W 200) immediately before use. Trifluoroacetic acid was Fluka (Purum grade) and used as obtained.
The cell used both for the kinetic study and for the preparation of the cation radical solutions was a cylindrical, round-bottom, jacketed container with openings for the auxiliary electrode compartment, reference electrode, inert gas supply, thermometer, and a Beckman rotating disk electrode. The temperature was controlled with tap water at $13.0 \pm 0.5^{\circ} \mathrm{C}$. The cation radical solutions were prepared by partial oxidation of solutions of thianthrene in the solvent systems. Oxidations were carried out at constant current $(12.5 \mathrm{~mA})$ at a large area platinum gauze electrode. Current was passed for a time calculated to give the desired concentration of cation radical. The concentration of the cation radical was determined exactly after oxidation by the magnitude of the limiting current at the rotating disk electrode. The limiting current was followed as a function of time for several minutes, and no significant decrease in cation radical concentration was observed before adding water. The procedure used for carrying out the kinetic runs has previously been described. ${ }^{1,2,8}$

The kinetic experiments were carried out during the period $1972-1973$ and the data were abstracted from the doctoral thesis of O.H.

Acknowledgement. This paper was written while V.D.P. was guest professor at the Department of General and Organic Chemistry, The H. C. Ørsted Institute. We gratefully acknowledge the University of Copenhagen for this support.

\section{REFERENCES}

1. Svanholm, U., Hammerich, O. and Parker, V. D. J. Am. Chem. Soc. 97 (1975) 101.

2. Svanholm, U. and Parker, V. D. J. Am. Chem. Soc. 98 (1976) 997.

3. Evans, J. and Blount, H. N. J, Org. Chem. 42 (1977) 976.

4. Shine, H. J. In Stirling, C. J. M. and Patai, S., Eds., The Chemistry of the Sulfonium Group, Wiley, New York 1981, Chapter 14.

5. Svanholm, U. and Parker, V. D. J. Am. Chem. Soc. 98 (1976) 2942.

6. Svanholm, U. and Parker, V. D. Acta Chem. Scand. B 34 (1980) 5.

7. Dusserre, A. and Genies, M., Bull. Soc. Chim. Fr. (1979) I-282.

8. Svanholm, U. and Parker, V. D. Acta Chem. Scand. 27 (1973) 1454.

Received September 14, 1981. 